\title{
The Effects of Parental and Peer Attachment on University Adjustment among First-Year Undergraduate Students
}

\section{Su-Wan Ganª, Min-Shern Cheah ${ }^{\mathrm{b}}$, Keng-Leong Chen ${ }^{\mathrm{c}}$, and Li-Xin Wong ${ }^{\mathrm{d}}$}

${ }^{a}$ Department of Psychology and Counseling, Universiti Tunku Abdul Rahman, Perak, Malaysia; ${ }^{b}$ Department of Psychology and Counseling, Universiti Tunku Abdul Rahman, Perak, Malaysia; ${ }^{C}$ Department of Psychology and Counseling, Universiti Tunku Abdul Rahman, Perak, Malaysia; ${ }^{d}$ Department of Psychology and Counseling, Universiti Tunku Abdul Rahman, Perak, Malaysia

Corresponding author:

Su-Wan Gan

Department of Psychology and Counseling

Universiti Tunku Abdul Rahman

Perak, Malaysia

Email address: swgan@utar.edu.my 


\title{
The Effects of Parental and Peer Attachment on University Adjustment among First-Year Undergraduate Students
}

\begin{abstract}
Entering university is a life transition for young adults who have to relocate away from their homes as well as deal with a wide range of problems and challenges in their new environment. This is especially the case for first-year undergraduate students. Past studies have found that perceived attachment to parents and peers primarily contributed to a successful transition among young adults enrolling in universities. Parental attachment provides a foundation for positive social relationships at university while social support from peers can help freshmen to quickly adapt to their new environment. Survey data using a purposive sampling technique were collected from 267 freshmen (average age $=20.81$ years; 62.5\% females) from four top public universities in Malaysia. First-year students who reported a higher level of parental attachment experienced a lower level of adjustment to university. This study also revealed that a higher level of peer attachment contributed to a greater level of adjustment to university. The results showed that peer attachment is the stronger predictor for university adjustment than parental attachment. The findings provided insights to interested parties such as policy makers in educational institutions in order to develop a better learning climate such as peer interactions or peer teaching programs to assist first-year students in making successful transitions to their life at university.
\end{abstract}

Keywords: parental attachment, peer attachment, university adjustment, first-year students

\section{Introduction}

Entering university is a life transition for young adults who have to relocate away from their homes as well as deal with a wide range of problems and challenges in their new environment. This is especially the case for first-year undergraduate students (Wang, Chen, Zhao, \& Xu, 2006). Recently, there has been renewed interest in examining the importance of university adjustment due to the public concern regarding suicide cases among undergraduate students. A recent local study (Shamsuddin et al., 2013) reported that approximately 10 per cent of current university students had severe depression and 30 per cent of them had severe anxiety. Students who are unable to cope with their new environment could easily become exposed to anxiety and depression (Julia \& Veni, 2012). Another study has shown that first-year students were more likely to face several social problems due to the separation from their family and secondary school friends (Mudhovozi, 2012). They will have to adapt to all these environmental changes while handling an unfamiliar and heavy academic workload. Inevitably, significant social and psychological relearning processes that cause feelings of confusion and anxiety may also affect their process of adjustment to university life (Pascarella \& Terenzini, 1991).

University adjustment refers to an individual's ability to adapt to a new environment by dealing with the stress caused by the demands of the new environment (Lenz, 2014). 
University adjustment is important for first-year undergraduate students so they can utilize and assimilate academic material successfully and form affable relations with peers and lecturers in university (Al-Khatib, Awamleh, \& Samawi, 2012). A higher level of university adjustment positively contributes to students' academic performance and well-being as well as increasing their persistence to pursue their studies (Elias et al., 2010; Franky \& Chamundeshwari, 2014; Páramo Fernández et al., 2017). Poor university adjustment can lead to high academic stress, problematic behavior, poor academic achievement and college dropout (Mudhovozi, 2012; Clinciu, 2013; Tom, 2015). First-year undergraduate students who are struggling with university adjustment are more likely to experience a higher level of persistent social anxiety throughout their first semester (Nordstrom et al., 2014).

Past studies found that freshmen's perceived attachment to their parents and peers was a primary contributing factor to successful transition among young adults enrolling in universities (Agarwal \& Poojitha, 2017). Attachment can increase an individual's stability and adaptability in terms of their social, emotional and psychological state (Love, 2008). Parental attachment provides a foundation for positive social relationships at university while social support from peers can help freshmen to quickly adapt to their new environment. Several pieces of evidences suggest that students with a higher level of secure attachment with their parents reported having a better adjustment (Hutchison, 2002; Phillips, 2007; Hiester et al., 2009). One longitudinal study (Smojver-Ažić et al., 2015) found that parental attachment provides a foundation for positive social relationships in college. On the flip side, a study by Love (2008) claimed that parental attachment consisting of overprotectiveness would lead to a rise in the anxiety and psychological distress of undergraduate students during this life transition stage. Students with an extreme level of parental attachment may find it difficult to separate from their parents and may suffer homesickness as well as a maladjustment to university life.

Peer support is a major influence in late adolescence (Rehman \& Younus, 2016) and is believed to be a significant predictor for young adults' university adjustment. Peer attachment is defined as a relational bond between individuals of identical interpersonal standing (Schnyders, 2012) and there is a need for them to spend time together to develop this bond (Nickerson \& Nagle, 2005). Social support from peers could help first-year students adapt to their new environment more quickly. A number of studies (Hutchison, 2002; Wilkinson, 2010; Ahn \& Lee, 2016; Wider et al., 2017) have shown that peer attachment positively contributes to a greater level of university adjustment. A recent study indicated that students who reported a high level of peer attachment significantly predicted a higher level of university adjustment, while students who reported poor relationships had lower levels of university adjustment (Maunder, 2017). Students who demonstrate attachment to peers tend to build up trust and have good communication with friends; thus, it can assist them in developing a sense of belonging in their new social circles and adapting to challenges in their new environment.

The quality of relationships that young adults have with both their parents and peers is a significant factor in determining their adjustment when going through the transition phase in university (Laible et al., 2000). Research by Phillips (2007) stated that attachment with parents 
and peers has a significant effect on the emotional adjustment and social competence of freshmen who are transitioning from their household to university. Therefore, this study aims to analyze the relations between parental and peer attachment and university adjustment. This study hypothesizes that there are significant relations between parental and peer attachment and university adjustment. In addition, parental attachment and peer attachment are significant predictors for university adjustment among freshmen.

\section{Methods}

This study applied a cross-sectional research design. Survey data were collected from 267 freshmen (average age $=20.81$ years; $62.5 \%$ females) from four top public universities in Malaysia using a purposive sampling technique. According to the ranking of Malaysia's top universities, there are the Universiti Malaya at Kuala Lumpur, the Universiti Putra Malaysia at Selangor, the Universiti Kebangsaan Malaysia at Selangor, and the Universiti Sains Malaysia at Penang Island and they are first, second, third, and fourth in the rankings respectively (QS University Rankings, 2017). These public universities were chosen in order to consider the possible stress level of students from top universities as they were more likely to experience university maladjustment. Over $50.0 \%$ of respondents are Malays $(n=143)$, followed by $32.2 \%$ Chinese, $10.5 \%$ Indians and $3.7 \%$ were respondents from other ethnic groups.

\section{A. Instrumentations}

A self-administered questionnaire consisting of The Inventory of Parent and Peer Attachment (IPPA), The College Adjustment Test (CAT) and demographic information was employed.

1) Parental and peer attachment: The IPPA by Armsden and Greenberg (1987) was used to measure the level of parental and peer attachment of respondents. There is a total of 28 items on the parental attachment scale and 25 items on the peer attachment scale. Respondents were required to provide responses on a 5-point Likert scale that ranged from 1 (almost never or never true) to 5 (almost always or always true). The range for parental attachment scores was 28 to 140 while the range for peer attachment was 25 to 125 . One example item from the parental attachment scale is "My parents encourage me to talk about my difficulties" while another example from the peer attachment scale is "When we discuss things, my friends consider my point of view." The higher the total score on each scale, the greater the attachment to parents or peers respectively. The Cronbach's alpha values for parental and peer attachment are 0.58 and 0.80 respectively.

2) University adjustment: The CAT by Pennebaker, Colder, and Sharp (1990) was used to measure respondents' university adjustment based on their feelings during the preceding week. It consists of 19 items on a 7-point Likert scale ranging from 1 (not at all) to 7 (a great deal). The scores for this measure ranged from 19 to 133. An example of an item includes "Worried about how you will perform academically at college" and "Felt lonely." The higher the summation score, the higher the university adjustment perceived by the respondents. The reliability of the CAT was identified by Cronbach's alpha of 0.79 . 


\section{B. Data Collection Procedures}

A paper questionnaire was distributed to the target participants on selected dates. The researchers reached out for volunteers to participate in the study. Prior to participation, the potential volunteers were briefed about confidentiality which was assured by the researchers. During the process of completing the questionnaire, researchers were on standby to provide further elaboration or clarification if necessary.

\section{Data Analytic Plan}

The data was analyzed with the IBM Statistical Package for Social Science version 22.0. The relations between study variables were analyzed with a Pearson correlational test while multiple regression was applied to test the predicting effects of parental and peer attachment on university adjustment.

\section{Results}

Table 1 shows that freshmen reported a moderate level of university adjustment with a mean score of 75.04 ( $\mathrm{SD}=11.99$ ). Table 1 also shows the results of the Pearson correlation to indicate the correlations among the study variables. Parental attachment (mean $=88.85 ; \mathrm{SD}=$ 8.35) was negatively correlated with university adjustment $(r=-0.14 ; p=0.021)$ while peer attachment (mean $=84.07 ; \mathrm{SD}=10.50$ ) was positively associated with university adjustment $(\mathrm{r}=0.16, \mathrm{p}=0.008)$. As shown in Table 2, age, gender, and academic performance were entered in Step 1 as controlled variables by using multiple linear regression. In Step 2, parental and peer attachment were entered to examine their predicting effects on university adjustment. Together, the effect of age, gender, and academic performance of undergraduates explained $5.4 \%$ of the variability of university adjustment. In Step 2, there was an increment in variance amount $\left(\mathrm{R}^{2}=0.12\right)$. By controlling the effect of age, gender, and academic performance of respondents in a multivariate model, parental and peer attachment can explain $6.6 \%$ of the variability of university adjustment. Both parental $(\beta=-0.20, p=0.002)$ and peer $(\beta=0.25, p$ $<0.001$ ) attachment were significant predictors for university adjustment. First-year undergraduates who perceived a higher level of parental attachment were less likely to adjust to university life. On the other hand, undergraduates who perceived a higher level of peer attachment experienced greater university adjustment.

Table I. Descriptive and Pearson Correlation Analysis $(\mathrm{N}=267)$

\begin{tabular}{|l|l|l|l|l|}
\hline Variables & Mean (SD) & $\mathbf{1}$ & $\mathbf{2}$ & $\mathbf{3}$ \\
\hline 1. Parental attachment & $88.85(8.35)$ & - & - & - \\
\hline 2. Peer attachment & $84.07(10.50)$ & & - & - \\
\hline 3. University adjustment & $75.04(11.99)$ & $-0.14^{*}$ & $0.16^{* *}$ & - \\
\hline \multicolumn{6}{|c|}{ SD $=$ standard deviation; ** $p<0.01 * p<0.05$}
\end{tabular}


Table II. Regression Analysis for Examining the Predictors of University Adjustment $(\mathrm{N}=267)$

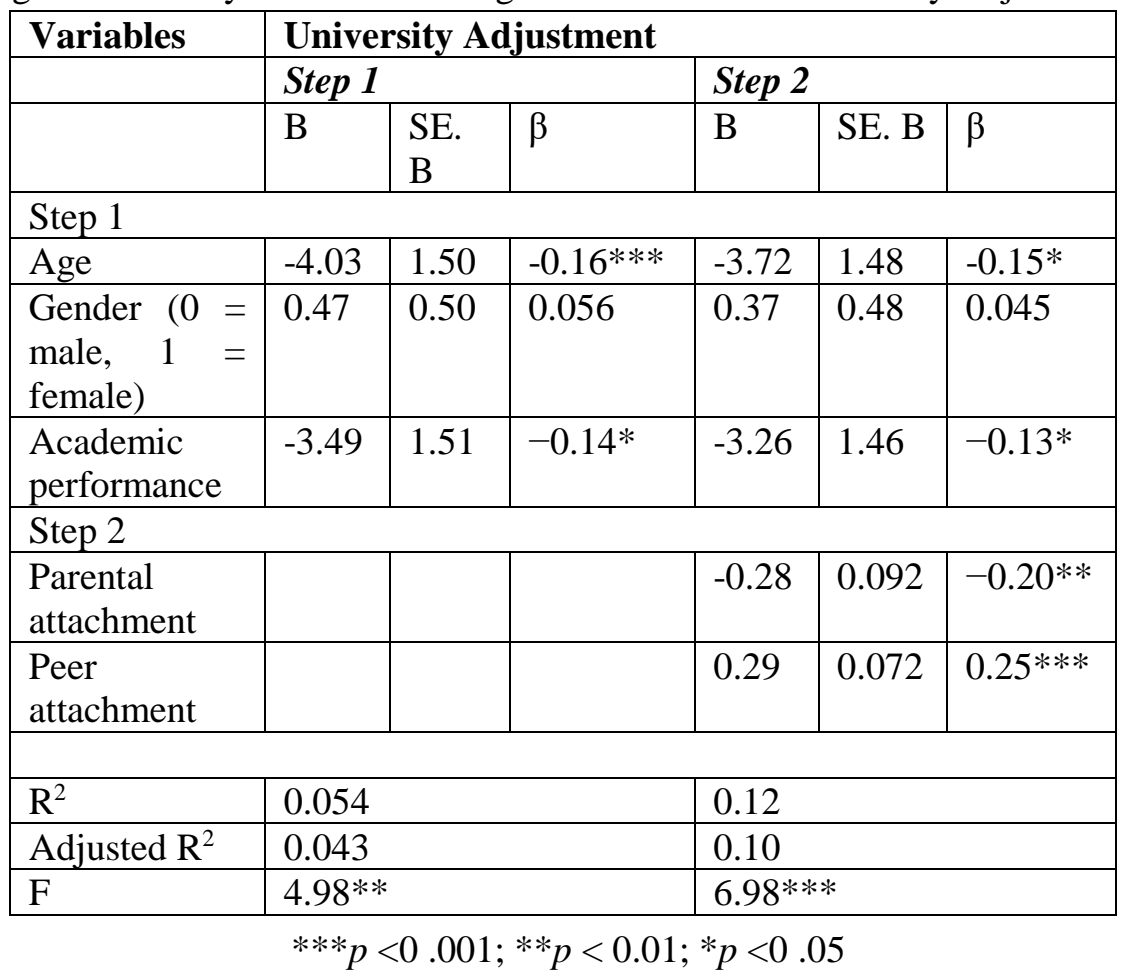

\section{Discussion}

According to the results of the Pearson correlation analysis, parental attachment has a negative correlation with university adjustment. Therefore, there is enough evidence to accept the hypothesis which indicated that the higher the parental attachment perceived by first-year undergraduates, the lower their university adjustment. This finding is inconsistent with previous studies (DeWall, 2005; Phillips, 2007; Hiester et al., 2009) which examined the correlation between parental attachment and university adjustment. However, a study by Love (2008) reported similar findings that found a negative correlation between parental attachment and adjustment to university life. On the other hand, there was a significant positive correlation between peer attachment and university adjustment. Thus, this hypothesis was accepted. First-year undergraduates who reported high levels of peer attachment also reported significantly higher levels of university adjustment. The findings were consistent with previous studies (Maunder, 2017; Wider et al., 2017).

After controlling the respondents' age, gender, and academic performance, the regression analysis found that parental and peer attachment were significant predictors of university adjustment. Thus, as hypothesized, parental and peer attachment are significant predictors for university adjustment. Hence, there is enough evidence to support the hypothesis. It is somewhat surprising that first-year students who reported a higher level of parental attachment are more likely to experience a lower level of university adjustment. This finding is contrary to previous studies which have suggested that students with a high level of parental attachment tend to adjust better to university life (Phillips, 2007; Garriot et al., 2010). However, this result may be explained by first-year undergraduates' anxiety and homesickness in terms of separating from their parents and adjusting to a new environment. Similarly, Love (2008) 
argues that a high level of parental attachment formed from extreme overprotectiveness would lead to an increase in anxiety and emotional and psychological distress of first-year undergraduates during the transition from home to university. In the same vein, a study by Smojver-Ažić et al. (2015) found that students who were far away from their home and parents displayed a lower emotional adjustment to college or tertiary academic institutions compared to those students who were able to stay at home with their parents. It is possible to hypothesize that attachment should shift from parents to peers during young adulthood. According to the psychosocial development stage (Erikson, 1968), the respondents of this study are in the "intimacy versus isolation" stage which means that forming interpersonal relationships with others (i.e., friends or an intimate partner) is more important than relationships with family members. This study also revealed that a higher level of peer attachment contributed to a greater level of university adjustment. This result corroborates the findings of the previous work in examining the predicting effect of peer attachment on university adjustment. The presence of trusting and loving relationships with peers could help university students to adjust to life at university in relation to their feelings of self-worth (Garriot et al., 2010). Peer attachment that reflects a secure social bonding with friends leads to greater university adjustment (Selby, 2001; Wider et al., 2017). A sense of belonging and social integration associated with peer attachment is crucial in developing a successful adaptation to the university setting. It implies that first-year undergraduates who received positive peer support and attachment experience low levels of negativity, loneliness, and anxiety as well as a high level of positivity and adaptability. In turn, they are more likely to report greater university adjustment by handling various challenges positively. Together these results suggest that it is vital to replace the insecurity and emptiness of first-year undergraduates by creating opportunities for them to spend time with their immediate nearby friends and peers. The nature and quality of parental attachment as regards undergraduates will be affected and will slowly weaken while the more direct effects of peer attachment are enforced throughout the adaptation process while at university.

This study has several noteworthy values. The results showed that peer attachment is a stronger predictor for university adjustment than parental attachment. It provides insight by demonstrating that young adulthood is the stage when the individual shifts attachment from parents to peers or even to romantic partners. Therefore, parents, especially Asian parents, should avoid overprotective parenting practices and encourage their children to expand their social circles in order to overcome challenges independently. The findings have important implications in terms of developing practical ideas to assist interested parties such as decision makers in educational institutions. The findings could help to develop a far better learning climate such as peer interactions or peer teaching programs to help first-year students make successful transitions to their life at university. The results of this study also highlight the important role of university orientation or new student orientation for first-year undergraduate students in adapting to the challenges in this transition. Most orientation programs that are handled by senior students not only help first-year undergraduates to become familiar with their new environment and the education system but also help them to connect with samecourse seniors, fellow classmates, and faculty members. This is important for undergraduates 
to become familiar with all the available resources and to fulfill their psychological needs that are required to handle different kinds of challenges during their years of study.

As with most research, there are limitations that must be addressed. For example, this research was cross-sectional in design and, as such, provided information at that point in time, which limits inferences of causality (Creswell, 2009). Although the present study did not attempt to construct any longitudinal arguments, there is a potential indirect effect that needs to be considered. Given that the nature of our data does not reach any conclusive result, longitudinal investigations would be helpful in facilitating the changes and causal effect of attachment on university adjustment throughout three or four years at university. Second, data collection was conducted through self-report questionnaires which are subject to producing fake results, and therefore, lead to a social desirability bias although it remains the field's most commonly used tool (Podsakoff et al., 2012). Multiple data collection is needed to corroborate our findings (Creswell \& Plano Clark, 2010). Future research can apply a mixed method by combining qualitative and quantitative approaches. First, a qualitative approach that can yield more individualized and in-depth information through open-ended interviews can be used to explore the challenges and obstacles that are experienced by first-year undergraduates. Following this, quantitative research can be conducted to validate the hypotheses regarding university adjustment and increase the generalizability of the results.

\section{Conclusion}

These findings help to explain the relations between parental attachment, peer attachment, and university adjustment. First-year students who reported a higher level of parental attachment experience a lower level of university adjustment. This study also revealed that a higher level of peer attachment contributed to a greater level of university adjustment. Therefore, positive peer relationships are important for first-year undergraduates in overcoming life transition challenges and adapting to university life.

\section{References}

Agarwal, S., \& Poojitha, R. (2017). Parent and peer attachment and assertiveness in college students. The International Journal of Indian Psychology, 4(3), 138-150.

Ahn, J., \& Lee, S. (2016). Peer attachment, perceived parenting style, self-concept, and school adjustments in adolescents with chronic illness. Asian Nursing Research, 10(4), 300-304.

Al-Khatib, B. A., Awamleh, H. S., \& Samawi, F. S. (2012). Student's adjustment to college life at Albalqa Applied University. American International Journal of Contemporary Research, 2(11), 7-16.

Armsden, G., \& Greenberg, M. (1987). The inventory of parent and peer attachment: Individual differences and their relationship to psychological well-being in adolescence. Journal of Youth and Adolescence, 16(5), 427-454.

Clinciu, A. (2013). Adaptation and stress for the first-year university students. Procedia-Social and Behavioral Sciences, 78, 718-722.

Creswell, J. W. (2009). Research design: Qualitative, quantitative, and mixed methods approaches (3rd ed.). Los Angeles: SAGE Publication.

Creswell, J. W., \& Plano Clark, V. L. (2010). Designing and conducting mixed methods research (2nd ed.). Los Angeles: SAGE Publication. 
DeWall, D. A. B. (2005). Family relationships and college adjustment of first-generation college students (Doctoral dissertation). Iowa State University, United States.

Elias, H., Noordin, N., \& Mahyuddin, R. H. (2010). Achievement motivation and self-efficacy in relation to adjustment among university students. Journal of Social Sciences, 6(3),333-339.

Erikson, E. H. (1968). Identity: Youth and crisis (1st ed.). New York: Norton.

Franky, D., \& Chamundeshwari, S. (2014). Psycho-social correlates of academic achievement of students. International Journal of Current Research and Academic Review, 2(2),148-158.

Garriot, P. O., Love, K. M., Tyler, K. M., Thomas, D. M., Roan-Belle, C. R., \& Brown, C. L. (2010). Testing an attachment model of Latina/o college students' psychological adjustment. Hispanic Journal of Behavioral Sciences, 32(1), 104-117.

Hiester, M., Nordstrom, A., \& Swenson, L. M. (2009). Stability and change in parental attachment and adjustment outcomes during the first semester transition to college life. Journal of College Student Development, 50(5), 521-538.

Hutchison, C. M. (2002). The relationship of adolescent attachment patterns to college student adjustment (Master's thesis). Rowan University, United States.

Julia, M. \& Veni, B. (2012). An analysis of the factors affecting students' adjustment at a university in Zimbabwe. International Education Studies, 5(6), 244-250.

Laible, D., Carlo, G., \& Raffaelli, M. (2000). The differential relations of parent and peer attachment to adolescent adjustment. Journal of Youth and Adolescence, 29(1), 45-59.

Lenz, A. S. (2014). Mediating effects of relationships with mentors on college adjustment. Journal of College Counseling, 17(3), 195-207.

Love, K. (2008). Parental attachments and psychological distress among African American college students. Journal of College Student Development, 49(1), 31-40.

Maunder, R. (2017). Students' peer relationships and their contribution to university adjustment: The need to belong in the university community. Journal of Further and Higher Education, 42(6), 756-768.

Mudhovozi, P. (2012). Social and academic adjustment of first-year university students. Journal of Social Sciences, 33(2), 251-259.

Nickerson, A., \& Nagle, R. (2005). Parent and peer attachment in late childhood and early adolescence. The Journal of Early Adolescence, 25(2), 223-249.

Nordstrom, A., Goguen, L., \& Hiester, M. (2014). The effect of social anxiety and self-esteem on college adjustment, academics, and retention. Journal of College Counseling, 17(1), 48-63.

Páramo Fernández, M. F., Araújo, A. M., Tinajero Vacas, C., Almeida, L. S., \& Rodríguez González, M. S. (2017). Predictors of students' adjustment during transition to university in Spain. Psicothema, 29(1), 6772.

Pascarella, E. T., \& Terenzini, P. T. (1991). How college affects students. Volume 1 (1st ed.). San Francisco: Jossey-Bass.

Pennebaker, J. W., Colder, M., \& Sharp, L. K. (1990). Accelerating the coping process. Journal of Personality and Social Psychology, 58(3), 528-537.

Phillips, C. (2007). Attachment styles and transitioning into college. The Review: A Journal of Undergraduate Student Research, 9(1), 24-27.

Podsakoff, P. M., MacKenzie, S. B., \& Podsakoff, N. P. (2012). Sources of method bias in social science research and recommendations on how to control it. Annual Review of Psychology, 63, 539-569.

QS University Rankings. (2017). Asia 2018, “Top Universities.” Retrieved from https://www.topuniversities.com/university-rankings/asian-university-rankings/2018

Rehman, S., \& Younus, B. F. (2016). Parental attachment and peer attachment bonds with the identity development during late adolescence. Sociology and Criminology-Open Access, 4(2), 154-158.

Schnyders, C. (2012). Parent and peer attachment as predictors of the perceived experience of emerging adulthood among undergraduates between the ages of 18-20: A multiple regression study (Doctoral dissertation). Kent State University College, United States.

Selby, J. C. (2001). The relationship of parent attachment, peer attachment, and self-concept to the adjustment of first-year college students (Doctoral dissertation). University of North Texas, Texas. 
Shamsuddin, K., Fadzil, F., Ismail, W. S., Shah, S. A., Omar, K., Muhammad, N. A., Jaffar, A., Ismail, A., \& Mahadevan, R. (2013). Correlates of depression, anxiety and stress among Malaysian university students. Asian Journal of Psychiatry, 6(4), 318-323.

Smojver-Ažić, S., Dorčić, T., \& Živčić-Bećirević, I. (2015). Attachment to parents and depressive symptoms in college students: The mediating role of initial emotional adjustment and psychological needs. Psychological Topics, 24(1), 135-153.

Tom, R. F. (2015). Adjustment experiences and coping strategies of first-year students at the University of Limpopo (Master's thesis). University of Limpopo, South Africa.

Wang, A., Chen, L., Zhao, B., \& Xu, Y. (2006). First-year students' psychological and behavior adaptation to college: The role of coping strategies and social support. US-China Education Review, 3(5), 51-57.

Wider, W., Mustapha, M., Halik, M., \& Bahari, F. (2017). Attachment as a predictor of university adjustment among freshmen: Evidence from a Malaysian public university. Malaysian Journal of Learning and Instruction, 14(1), 111-144.

Wilkinson, R. (2010). Best friend attachment versus peer attachment in the prediction of adolescent psychological adjustment. Journal of Adolescence, 33(5), 709-717. 